\title{
SINTOMAS DE DEFICIÊNCIA TARDIA DE FÓSFORO EM SOJA ${ }^{(1)}$
}

\author{
Ciro Antonio Rosolem ${ }^{(2)}$ \& Carolina Amaral Tavares ${ }^{(3)}$ \\ RESUMO
}

Foi notado, em área de cultivo experimental em Botucatu (SP), que a soja, na época de enchimento das vagens, apresentava folhas com cor amarelada, que evoluía para palha, com tons arroxeados no limbo foliar e nos pecíolos. Esses sintomas eram compatíveis com as descrições mais genéricas de deficiência de P para outras espécies, apesar de não estarem descritos para soja. Foi conduzido um experimento em vasos com areia lavada e solução nutritiva, com o objetivo de reproduzir os sintomas observados em condição de campo. Foram cultivadas três plantas de soja por vaso, em ambiente aberto. Os sintomas de deficiência de $\mathbf{P}$ apareceram inicialmente nas folhas mais velhas, que ficaram amareladas, conservando algumas nervuras verdes. $O$ tom amarelado foi-se intensificando, adquirindo tons avermelhados e, posteriormente, arroxeados. Notou-se ainda colapso do pecíolo das folhas com sintomas de deficiência. A fase de pegamento de vagens de soja mostrou-se mais sensível à deficiência de $\mathrm{P}$ do que a fase de enchimento de grãos podendo ocorrer recuperação de parte da produtividade pela produção de menor número de grãos e vagens chochas e aumento no tamanho de grão, se a deficiência ocorrer tardiamente e não for muito severa.

Termos de indexação: deficiência mineral, diagnose visual, macronutriente, nutrição mineral.

\section{SUMMARY: PHOSPHORUS DEFICIENCY SYMPTOMS IN SOYBEAN}

It was observed in an experimental soybean field in Botucatu County (SP), Brazil, that leaves presented yellowish color with purple shades in the leaflets and petioles at grain filling. These symptoms, although not described in soybean, were compatible with general descriptions of phosphorus deficiency. An experiment was conducted in pots with washed sand and nutrient solution to reproduce these symptoms in controlled conditions. Three

\footnotetext{
(1) Trabalho apresentado no XXIX Congresso Brasileiro de Ciência do Solo. Recebido para publicação em e março de 2005 aprovado em fevereiro de 2006 .

(2) Professor Titular do Departamento de Produção Vegetal da Faculdade de Ciências Agronômicas - UNESP. Caixa Postal 237, CEP 18603-970 Botucatu (SP). E-mail: rosolem@fca.unesp.br

(3) Acadêmica do curso de Agronomia, Faculdade de Ciências Agronômicas, UNESP. E-mail: ctavares@fca.unesp.br
} 


\begin{abstract}
soybean plants were grown per pot, in an uncontrolled environment. Phosphorus deficiency symptoms were first observed in old leaves that turned yellowish, while some veins remained green. The yellow leaves turned progressively red and then purple and the petioles of deficient leaves collapsed. The grain filling period was very sensitive to $P$ deficiency, but when the deficiency occurred late in the season and was not too severe, yield loss was partially compensated by a lower number of aborted grains and pods as well as by a larger seed size.
\end{abstract}

Index terms: mineral deficiency, visual diagnosis, macronutrients, mineral nutrition.

\section{INTRODUÇÃO}

O baixo teor de P é uma das principais limitações à produtividade agrícola nas regiões de solos sob cerrado, aparecendo como fator limitante em $96 \%$ da área destes solos na América Tropical (Sanches \& Salinas, 1981).

O P faz parte de ésteres de carboidratos, fosfolipídeos, coenzimas e ácidos nucléicos na planta. Com deficiência de $P$, as plantas anuais apresentam emergência e crescimento lentos; as folhas são verdeescuras, com pecíolos e nervuras arroxeados, principalmente na parte abaxial; o crescimento radicular é prejudicado e as plantas mostram-se estioladas ou com crescimento bastante prejudicado (Bingham, 1966).

Diversos autores descreveram a deficiência de $\mathrm{P}$ em soja. Rosolem (1982) relatou que, em deficiência de $\mathrm{P}$, as folhas mais velhas e intermediárias da soja mostram-se, de início, com cor verde mais escura: com o tempo, tais folhas mostram clorose generalizada, que caminha da ponta para a base, e os sintomas são acentuados nos estádios de floração e enchimento dos grãos. De acordo com Sinclair (1993), a soja requer quantidades relativamente altas de $\mathrm{P}$, especialmente na época de fixação das vagens. Os sintomas de deficiência não são bem definidos, sendo o retardamento no crescimento o principal deles. As plantas estiolam e tem folhas menores, que se tornam verde-escuras ou verdeazuladas. O florescimento e a maturação são atrasados. Segundo Malavolta et al. (1997), em princípio, as folhas mais velhas apresentam cor amarelada, com pouco brilho, cor verde-azulada ou manchas pardas, número reduzido de frutos e sementes, atraso no florescimento e tamanho reduzido da planta, mas ressaltam que estes sintomas são muito difíceis de ser caracterizados em condição de campo. São ainda relatados como efeitos da deficiência de $\mathrm{P}$ a diminuição do índice de área foliar, da absorção e concentração de $\mathrm{P}$, além do aumento da densidade radicular nas camadas superficiais do solo (Gutierrez-Boem \& Thomas, 1998).

$\mathrm{Na}$ safra 2001/2002, foi notado, em campo experimental em Botucatu (SP), que plantas numa área de soja, na época de enchimento das vagens, apresentavam folhas com cor amarelada, que evoluía para palha, com tons arroxeados no limbo foliar e nos pecíolos (Figura 1). Apesar de não terem sido notados os sintomas clássicos de deficiência de $\mathrm{P}$ descritos para a soja (Sinclair, 1993, Malavolta et al., 1997), estes sintomas eram compatíveis com as descrições mais genéricas de deficiência deste nutriente (Bingham, 1966). A área com sintomas não havia recebido calagem ou adubação fosfatada.

O presente experimento foi planejado e conduzido com o objetivo de avaliar sintomas de deficiência de $\mathrm{P}$ em soja cultivada em vasos, tentando reproduzir os sintomas observados em condição de campo.

\section{MATERIAL E MÉTODOS}

O experimento foi instalado na Faculdade de Ciências Agronômicas, UNESP-Botucatu, no Departamento de Produção Vegetal, em vasos de $12 \mathrm{~L}$ que continham areia lavada. Sementes de soja, cv. IAC 19, foram tratadas com fungicida e colocadas para pré-germinação por $48 \mathrm{~h}$ a $30^{\circ} \mathrm{C}$, e, posteriormente, transferidas para vasos com areia grossa peneirada, lavada com ácido clorídrico diluído e com água destilada. Foram cultivadas três plantas por vaso, em ambiente aberto, uma vez que a intensidade e a qualidade da luz podem afetar a manifestação dos sintomas (Marschner \& Cakmak, 1989).

Foi aplicada solução nutritiva de Hoagland completa, dos oito até os 57 dias após a emergência (DAE). Por ocasião do aparecimento das primeiras gemas florais (57 DAE), iniciaram-se os tratamentos, com aplicação da solução completa em quatro vasos e completa menos $\mathrm{P}$ em outros quatro. A solução foi aplicada em volume suficiente para saturar a areia, semanalmente, em substituição a uma irrigação. $\mathrm{O}$ delineamento experimental foi inteiramente casualizado com quatro repetições, totalizando oito parcelas.

Por ocasião do florescimento pleno (76 DAE), coletou-se a terceira folha a partir do ápice para a diagnose foliar (Rosolem, 1982). O P no tecido foi analisado de acordo com Malavolta et al. (1997). Foram avaliados os sintomas visuais de deficiência na planta. 


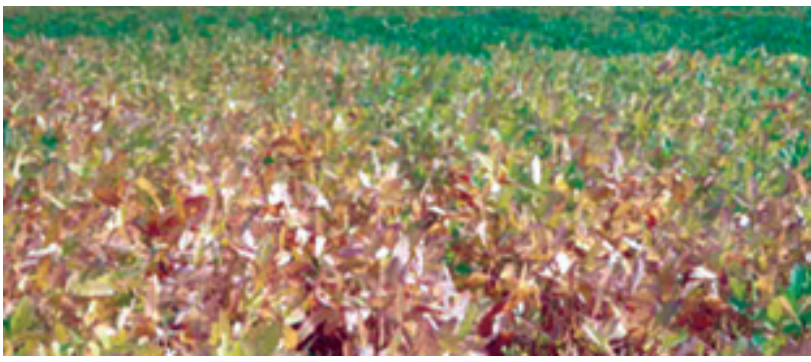

Figura 1. Sintomas observados em campo, na safra 2001/2002, em Botucatu (SP). Notam-se, no topo da figura, plantas verdes, sem sintomas.

A soja foi colhida aos $124 \mathrm{DAE}$, quando foram avaliados a altura das plantas (do colo à extremidade da haste principal), o número de vagens chochas, cheias e total, o número de grãos chochos, cheios e total, o peso total de grãos e o teor de P nas folhas e grãos.

Foi realizada análise de variância, sendo os resultados comparados pelo teste $\mathrm{F}$ a $5 \%$.

\section{RESULTADOS E DISCUSSÃO}

As plantas deficientes em $\mathrm{P}$ (Figura 2) mostraram-se mais esguias que as do tratamento completo, sem diferença na altura. Os sintomas de deficiência apareceram inicialmente nas folhas mais velhas, que ficaram amareladas, conservando algumas nervuras verdes; entretanto, não se manifestaram primeiramente nas pontas, progredindo para a base, como descrito por Rosolem (1982). O tom amarelado foi-se intensificando, adquirindo tons avermelhados e, posteriormente, arroxeados (Figura 3). Notou-se, ainda, colapso do pecíolo das folhas com sintomas de deficiência (Figura 3). Alguns destes sintomas não se encontravam descritos na literatura (Rosolem, 1982; Sinclair, 1993; Malavolta et al., 1997). Por outro lado, o sintoma mais comumente descrito, ou seja, folhas verde-escuras ou verde-azuladas, não foi observado no presente experimento.

$\mathrm{O}$ amarelecimento inicial das folhas e o colapso de pecíolo foram descritos anteriormente por Tanaka et al. (1993) como deficiência de Ca, em situação de baixa disponibilidade de água no solo que, assim, pode-se confundir com a deficiência de $\mathrm{P}$.

Observou-se que praticamente todas as características analisadas foram alteradas pela deficiência de $\mathrm{P}$, com exceção da altura de plantas, peso de grãos por planta e número de grãos por vagem (Quadro 1). É interessante notar que tanto o número quanto a percentagem de vagens e grãos chochos foram bem menores nas plantas deficientes, enquanto o peso de 100 grãos foi maior neste caso.

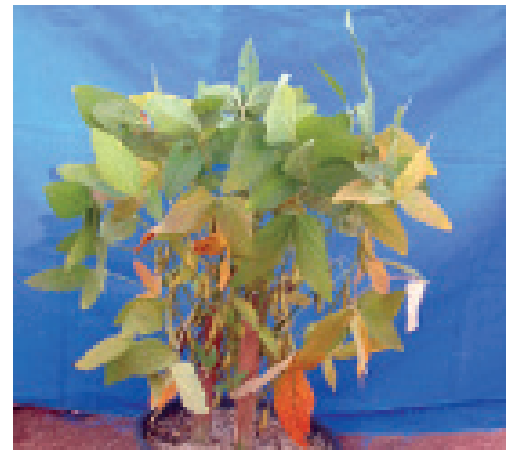

Figura 2. Planta de soja deficiente em P, com folhas amareladas e tons arroxeados nos pecíolos e nervuras.

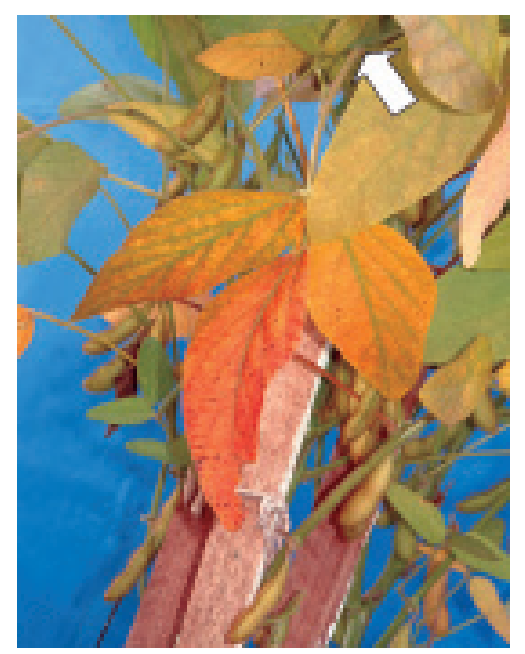

Figura 3. Detalhe de folha de soja com deficiência de P. Nota-se o sintoma de colapso do pecíolo (seta).

Seria esperada uma redução no número de vagens e grãos (Sinclair, 1993; Malavolta et al., 1997; Gutierrez-Boem \& Thomas, 1998), que ocorreram (Quadro 1), bem como a diminuição do tamanho dos grãos (Sinclair, 1993; Gutierrez-Boem \& Thomas, 1998), que foram maiores com deficiência de $P$. Apesar de os grãos apresentarem menor teor de $\mathrm{P}$, o maior peso de 100 grãos, aliado à obtenção de menor número e percentagem de grãos chochos nas plantas deficientes (Quadro 1), torna possível inferir que a deficiência prejudicou basicamente a formação de vagens, mas as poucas vagens formadas foram mais bem nutridas, quanto ao aporte de fotossintatos, que as das plantas não deficientes em P. Assim, a planta foi sensível à deficiência de $\mathrm{P}$ ocorrida após o florescimento, particularmente no pegamento de vagens, com maior percentagem de abscisão. Uma vez formadas as vagens, verificouse recuperação da produtividade, pela diminuição da percentagem de vagens e grãos chochos e do maior peso de 100 grãos. 
Quadro 1. Altura de plantas, número total de vagens cheias, chochas, total de grãos cheios, chochos, peso de grãos e teor de $\mathrm{P}$ nos grãos e nas folhas. Média de 12 plantas

\begin{tabular}{|c|c|c|c|}
\hline Tratamento & Sem P & Com P & CV (\%) \\
\hline Altura de plantas $(\mathrm{cm})$ & 37,1 & 39,3 & 12,2 \\
\hline Vagens cheias & $43,0^{*}$ & 64,8 & 15,3 \\
\hline Vagens chochas & $1,5^{*}$ & 7,6 & 17,1 \\
\hline Total de vagens & $44,5^{*}$ & 72,5 & 13,4 \\
\hline$\%$ de vagens chochas & $3,3^{*}$ & 10,5 & 16,0 \\
\hline Grãos cheios & $85,6^{*}$ & 120,1 & 9,0 \\
\hline Grãos chochos & $1,0^{*}$ & 15,5 & 16,7 \\
\hline Total de grãos & $86,6^{*}$ & 135,6 & 13,9 \\
\hline$\%$ de grão chochos & $1,1^{*}$ & 11,4 & 15,0 \\
\hline Peso $(g)$ & 15,8 & 17,7 & 12,6 \\
\hline Peso 100 grãos (g) & $18,2^{*}$ & 13,1 & 5,0 \\
\hline Número de grãos por vagem & 1,9 & 1,9 & 13,0 \\
\hline P nos grãos $\left(\mathrm{g} \mathrm{kg}^{-1}\right)$ & $1,4^{*}$ & 4,4 & 12,3 \\
\hline P nas folhas $\left(\mathrm{g} \mathrm{kg}^{-1}\right)$ & $0,8^{*}$ & 1,2 & 11,8 \\
\hline
\end{tabular}

* Diferença significativa em relação ao tratamento com P. Teste $\mathrm{F}(\mathrm{p}<0,05)$.

Deste modo, a deficiência de $\mathrm{P}$, quando imposta nas condições do presente experimento, parece não ter alterado, de modo significativo, a fotossíntese da planta. A fotossíntese na soja tem certa tolerância à deficiência de $\mathrm{P}$, uma vez que a fixação de $\mathrm{CO}_{2}$ foi bem menos influenciada pela deficiência de $\mathrm{P}$ que no caso do girassol (Guidi et al., 1994). Além disso, o nutriente acumulado na planta durante a fase vegetativa, não deficiente, pode ter sido suficiente para atender à translocação para os grãos em formação, de modo a diminuir o prejuízo na produtividade. Rosolem (1982) relatou que há forte translocação do $\mathrm{P}$ das partes vegetativas da soja para os grãos, mas há necessidade de absorção do nutriente até praticamente o final do ciclo, para que a produtividade não seja prejudicada. O teor de $\mathrm{P}$ nos grãos foi bem menor na condição de deficiência (Quadro 1).

É interessante também notar que, apesar dos relatos de que a deficiência de $\mathrm{P}$ diminui o crescimento vegetativo (Malavolta, 1997; GutierrezBoem \& Thomas, 1998), a altura das plantas não foi alterada, provavelmente porque a deficiência foi imposta tardiamente. É importante ressaltar, ainda, que o cultivar utilizado, IAC 19, foi classificado como ineficiente e não responsivo a $\mathrm{P}$ por Furlani et al. (2002)

Os sintomas de deficiência de $\mathrm{P}$ anteriormente descritos na literatura não contemplam as características observadas, a saber: arroxeamento de folhas e pecíolos e colapso de pecíolos (Figura 4). A fase de pegamento de vagens é mais sensível à deficiência de $\mathrm{P}$ do que a fase de enchimento de grãos, podendo ocorrer recuperação de parte da produtividade pelo menor número de grãos e vagens chochas e aumento no tamanho de grão, se a deficiência ocorrer tardiamente e não for muito severa.

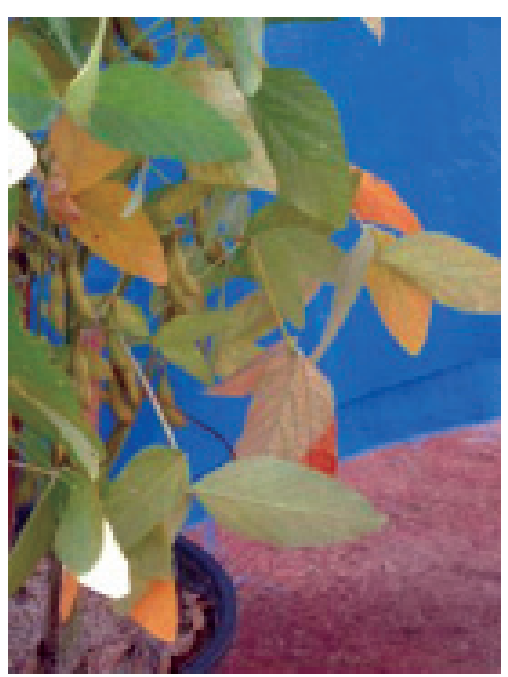

Figura 4. Detalhe de folhas de soja com deficiência de P. Notam-se os sintomas de colapso do pecíolo e arroxeamento de folhas e pecíolos.

\section{LITERATURA CITADA}

BINGHAM, F.T. Phosphorus. In: CHAPMAN, H.D., ed. Diagnostic criteria for plants and soils. Abilene, Homer D. Chapman, 1966. p.324-361.

FURLANI, A.M.C.; FURLANI, P.R.; TANAKA, R.T.; MASCARENHAS, H.A.A. \& DELGADO, M.D.P. Variabilidade em germoplasma de soja para eficiência na absorção e utilização de fósforo. Sci. Agric., 59:529-536, 2002. 
GUIDI, L.; PALLINI, M. \& SOLDATINI, G.F. Influence of phosphorus deficiency on photosynthesis in sunflower and soybean plants. Agrochimica, 38:211-223, 1994.

GUTIERREZ-BOEM, F.H. \& THOMAS, G.W. Phosphorus nutrition and water deficits in field-grown soybeans. Plant Soil, 207:87-96, 1998.

MALAVOLTA, E.; VITTI, G.C. \& OLIVEIRA, S.A. Avaliação do estado nutricional de plantas: Princípios e aplicações. Piracicaba, Potafos, 1997. 308p.

MARSCHNER, H.\& CAKMAK, I. High light intensity enhances chlorosis and necrosis in leaves of zinc, potassium and magnesium deficient bean plants. J. Plant Physiol., 134:308315, 1989.
ROSOLEM, C.A. Nutrição mineral e adubação da soja. 2.ed. Piracicaba, Potafós, 1982. 80p. (Boletim, 6)

SANCHES, P.A. \& SALINAS, J.G. Low input management technology for managing Oxisols and Ultisos em Tropical América. Adv. Agron., 34:279-406, 1981.

SINCLAIR, J.B. Soybeans. In: BENNETT, W.F., ed. Nutrient deficiencies \& toxicities in crop plants. Saint Paul, APS, 1993. p.99-103.

TANAKA, R.T.; MASCARENHAS, H.A.A. \& BORKERT, C. Nutrição mineral da soja. In: ARANTES, N.E. \& SOUZA, P.I.M., eds. Cultura da soja nos cerrados. Piracicaba, Potafós, 1993. p.105-135. 